\title{
Conserving Historic Urban Landscape for the Future Generation - Beyond Old Streets Preservation and Cultural Districts Conservation in Taiwan
}

\author{
Chao-Ching Fu
}

\begin{abstract}
On 10 November 2011 UNESCO's General Conference adopted the new Recommendation on the Historic Urban Landscape by acclamation, the first such instrument on the historic environment issued by UNESCO in 35 years. This paper will first review the preservation of "old streets" and the conservation of "cultural districts" in Taiwan. Then, the paper will discuss how the concept of "historic urban landscape" could be transformed into an approach or a tool for conserving historic cities and towns in Taiwan.
\end{abstract}

Index Terms-Historic urban landscape, old streets, cultural districts, Taiwan.

\section{INTRODUCTION}

On 10 November 2011 UNESCO's General Conference adopted the new Recommendation on the Historic Urban Landscape by acclamation, the first such instrument on the historic environment issued by UNESCO in 35 years. However, UNESCO stresses that the Recommendation on the Historic Urban Landscape will not replace existing doctrines or conservation approaches; rather, it is an additional tool to integrate policies and practices of conservation of the built environment into the wider goals of urban development in respect of the inherited values and traditions of different cultural contexts. In fact, the concept of historic urban landscape initiated in 2008 when the 179th session of the UNESCO Executive Board made a decision proposed by the Director-General for the preparation of a revised Recommendation concerning the safeguarding and contemporary role of historic areas. It was followed in 2009 by the 181st session of the Executive Board to approve the full preliminary study of the technical and legal aspects of a revised Recommendation concerning the safeguarding and contemporary role of historic areas. In the same year, the preliminary study was adopted by the 35th session of the General Conference of the UNESCO as a resolution. In 2010, the 185th session of the Executive Board pass a decision on the invitations to intergovernmental meeting of experts (category II) related to a draft recommendation on the conservation on the conservation of the historic urban landscape. And preliminary report on the draft Recommendation on the Historic Urban Landscape was made. In 2011, the 36th session of the General Conference of the UNESCO accepted the "Proposal concerning the

Manuscript received December 1, 2014; revised January 21, 2015.

Chao-Ching $\mathrm{Fu}$ is with the Department of Architecture, National Cheng-Kung University, Taiwan (e-mail: ccfu@mail.ncku.edu.tw). desirability of a standard-setting instrument on historic urban landscapes" and the report and revised of the draft Recommendation on the Historic Urban Landscape was adopted.

According to the recommendation, the historic urban landscape is the urban area understood as the result of a historic layering of cultural and natural values and attributes, extending beyond the notion of "historic center" or "ensemble" to include the broader urban context and its geographical setting (Article 8). This wider context includes notably the site's topography, geomorphology, hydrology and natural features, its built environment, both historic and contemporary, its infrastructures above and below ground, its open spaces and gardens, its land use patterns and spatial organization, perceptions and visual relationships, as well as all other elements of the urban structure. It also includes social and cultural practices and values, economic processes and the intangible dimensions of heritage as related to diversity and identity (Article 9). And this definition provides the basis for a comprehensive and integrated approach for the identification, assessment, conservation and management of historic urban landscapes within an overall sustainable development framework (Article 10).

\section{TAIWAN'S URBAN CONSERVATION IN THE 1970S AND 1980s}

In addition to preserving individual buildings, the concept of urban conservation appeared in the 1970s and 1980s in Taiwan as a way to conserve entire historical areas. Lukang Historical District and Anping Historical Area are two examples. Lukang was the second largest town in Taiwan during the Qing Dynasty. In addition to many precious national monuments (such as the famous Longshan Temple), its winding alleys and the traditional houses on both sides of those alleys are very attractive. In the 1970s, Hao Pao-teh proposed an overall conservation plan for this historical area.

Research by Lin Hui-chen and other scholars also provided valuable information. Several sections of the historical district were listed as the conservation areas and the houses were restored by Hankwang Architects, supervised by Han Pao-teh; hence, Lukang became the first legal conservation area in Taiwan. The result of the house restorations received both praises and negative criticisms. Most of criticisms came from residents of the conservation areas, who complained about the restrictions placed on them, as well as the loss of privacy when a large number of people began to pour onto the alleys, which used to be only 
semi-public spaces. Nevertheless, Lukang has become a model for urban conservation in Taiwan (see Fig. 1) [1], [2], [5].

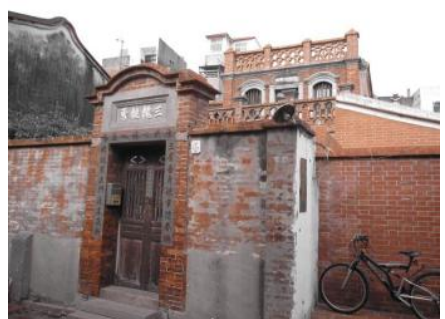

Fig. 1. House and alley of Lukang historical preservation district.

Compared with Lukang, Anping was not a successful example of urban conservation practice before the founding of the Anping Harbor National Historical Scenic Area in 2003. Located about $5 \mathrm{~km}$ west of downtown Tainan, Anping was the first Chinese settlement in Taiwan. It was also where the Dutch established their administration center in the seventeenth century. The small-scale residential buildings, traditional temples, symbolic decorations such as sword-lions, and human-scale alleys are still preserved in some parts of Anping. Exploring the winding alleys that snake between buildings off the main roads provides a real sense of the past, as many of them are so narrow that it is difficult for modern vehicles to pass through.

Beginning in the 1970s, scholars proposed conservation plans and carried out extensive research. However, most of the proposed plans were opposed by local residents, who were weary of seeing their labor-intensive and fishery industries decline and watching the younger generations leave for jobs in bigger cities. They asked for the expansion of the narrow streets and alleys, which they thought were a symbol of underdevelopment. The renewal of the district has since become a much-touted concept among local people and political leaders. Consequently, the first street in Taiwan, despite its great historical significance, was demolished in the early 1990s. The same situation occurred when many old temples and traditional houses were destroyed and new houses were constructed at odds with the area's historical context (see Fig. 2) [1]-[3].

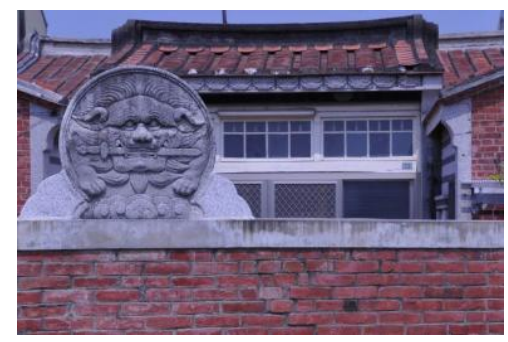

Fig. 2. Traditional house with sword-lion in Anping.

\section{Old STREETS PRESERVATION}

In Taiwan, many of the so-called "old streets" - Dihua Old Street (Taipei); Sanxia Old Street, Huko Old Street, and Daxi Old Street (Northern Taiwan); and Xinhua Old Street (Tainan) - have experienced similar processes since the late 1980s. Dihua Old Street is located outside Qing Dynasty
Taipei City. During the Japanese Period, it was mostly inhabited mostly by Taiwanese people, in contrast with the Japanese residential quarters inside the city wall. It now contains many old-fashioned shops, traditional Chinese medicine vendors, and wholesale cloth stores. It is also famous for the traditional Taiwanese-style foods and medicinal foods that are sold during the Chinese New Year festival period (see Fig. 3).

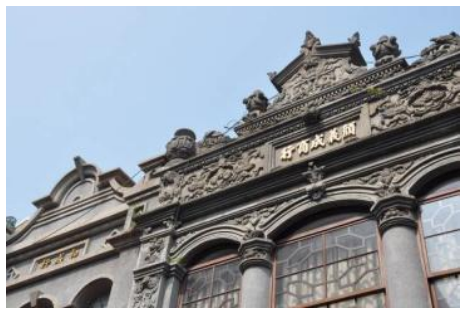

Fig. 3. Dihua old street, Taipei.

Sanxia is a traditional suburban district in New Taipei City. In the past, it was an important goods distribution center because of its strategical location. It developed quickly and became a stronghold for the production of various products; the streets of the town were lined with shops that sold dyes, manufacturing materials, and tea. Yet, after World War II, Sanxia lost its economic advantages, and its prosperity faded very quickly. Recognizing its cultural value and architectural significance, scholars and people from cultural circles recommended that Sanxia Old Street be preserve when a massive development was undertaken in the mid-1970s at the expense of many valuable old street-houses (see Fig. 4).

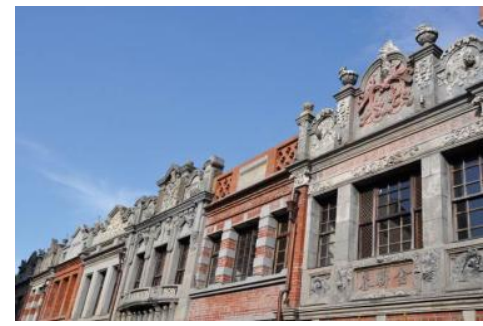

Fig. 4. Sanxia old street.

Daxi Old Street was one of the earliest developed areas in Taoyuan County. Trade with China thrived during the Qing Dynasty, when transport by boats was allowed. The town became a bustling hub for the camphor and tea trades, and the wealth derived from trading enabled local gentry and merchants to construct buildings decorated with both Western and local motifs. Nowadays, Daxi is still filled with diverse stores, and is especially famous for dry bean curd. Xinhua existed as early as the Dutch and Spanish periods. It was known as "Damujiang" (Tavakan) in the local aboriginal language. Its two most important streets were developed during the Japanese period. However, the buildings on Zhongzheng Old Street were demolished in 1955 due to a road expansion plan. Currently there are only about 40 buildings remaining on this old street, mostly on Zhongshan Road. This area not only features unique architectural forms and spaces, but also preserves traditional business models, symbolizing the glory of past years. In the beginning, residents living on these streets opposed the conservation 
plan. They demand a wider street so that they could park their cars and unload goods. After endless discussions and negotiations, and the establishment of local conservation groups who attempted to persuade those against the conservation, three streets were preserved, and have since attracted numerous visitors. Consequently, the residents benefited in terms of economic income, and their attitudes toward the conservation project have changed (see Fig. 5- Fig. 6).

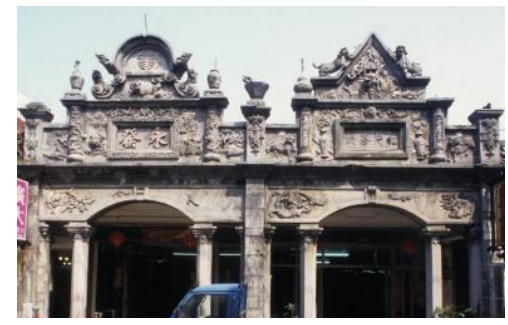

Fig. 5. Daxi old street.

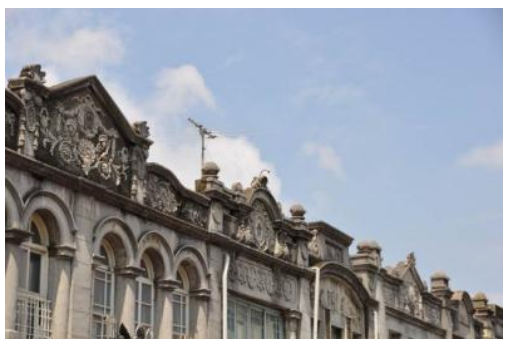

Fig. 6. Xinhua old street.

\section{From Old StREets to CUltural Districts}

Beginning in the early 1990s, the linear preservation of old streets was unable to meet the demands of conserving more than a single street in some cities. Consequently, the concept of a "cultural district" emerged. Different from the concept of the historic center, the concept of a cultural district is to embrace not only the built environment but also the cultural activities within defined district. The Confucius Temple Cultural District is one of the earliest examples in urban conservation practices in Taiwan. The district is centered on the historical Confucius Temple at the heart of Tainan City, which was the capital of Taiwan during the Qing Dynasty. Many monuments and historical buildings are connected by its narrow, old streets. The district has been the political center of the city since the Japanese colonial period. The Tainan Prefecture Hall built by the Japanese was used by the Nationalist government for various functions, including functioning as a city hall between 1969 and the 1980s. When the city developed outwards in the 1980s and the city government moved to its new location in 1998, the whole district started to deteriorate and the inhabitants moved out. Without proper connections, the monuments and historical buildings became isolated like islands in sea of ordinary architecture. Acknowledging the suggestion of scholars at the NCKU, the Tainan City government launched the "Rejuvenate Tainan with Culture" policy in the late 1990s. Several cultural districts were designated, of which the Confucius Temple Cultural District is the most successful one (see Fig. 7- Fig. 8), [2].

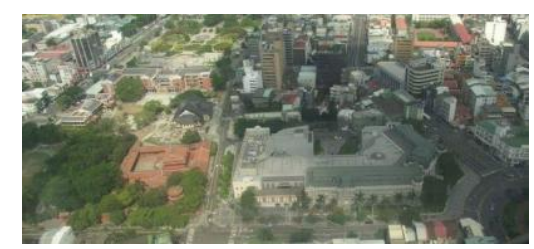

Fig. 7. Panorama view of Tainan Confucius temple cultural district.

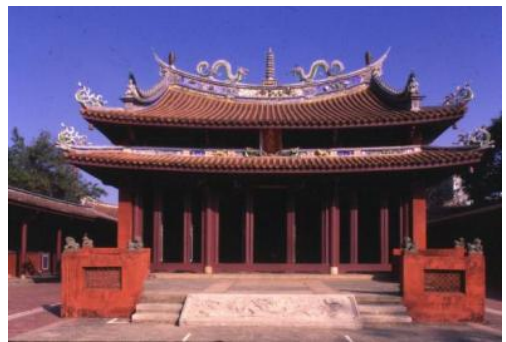

Fig. 8. Tainan confucius Temple.

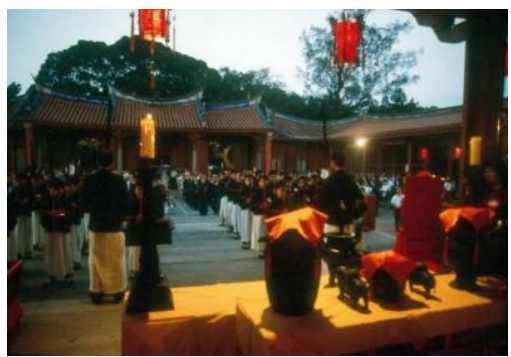

Fig. 9. Confucius worship at the Tainan confucius temple in the early morning.

The street furniture, sidewalk pavements, and street signs of the district were re-designed, and several historical buildings were adaptively reused. The former Tainan Climate Station (1898) became the Taiwan Weather Museum; the former Tainan Public Hall (1911) became the Wu Garden Art Center; the former Tainan Prefecture Hall (1916) became the National Museum of Taiwan Literature; and the former Tainan Martial Morals Hall (1930) became the auditorium and the cultural heritage resources classroom of Jhongyi Elementary School [2]. As an important building within the Confucius Temple Cultural District, the Tainan Martial Morals Hall was given a thorough restoration and was re-opened as a multi-functional auditorium for the school. One of the classrooms on the ground floor is now a cultural heritage resources classroom, where information on various cultural heritage sites located within the Confucius Temple Cultural District is exhibited. Not only students from Jhongyi Elementary School, but also students from all of the city's schools can visit the classroom for an orientation on the cultural heritage of the district (see Fig. 9).

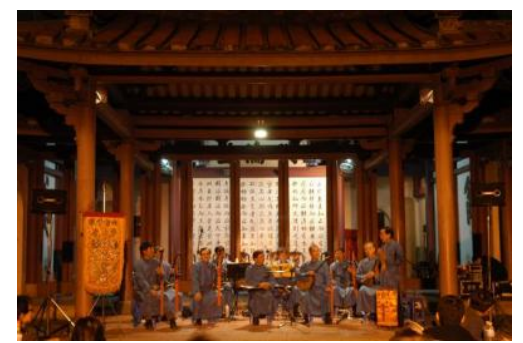

Fig. 10. Traditional music performance in the Tainan Confucius temple cultural district. 


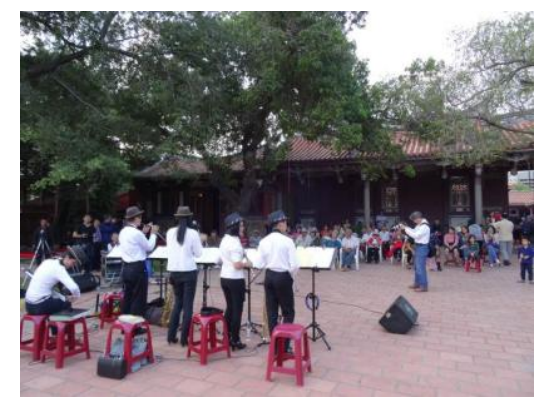

Fig. 11. Modern music performance in the Tainan Confucius temple cultural district.

Nowadays, Tainan's Confucius Temple Cultural District is a model for similar urban conservation projects in other Taiwanese cities. After several years of environmental improvement and cultural heritage conservation, the Confucius Temple Cultural District is now a famous urban attraction in Tainan City. Green trees, red roof tiles, old walls, and winding alleys form the basic impression of the district. The ritual of worshipping Confucius continues. Performing arts can be seen everywhere in the district. It is a must-see place for the tourists as well as a leisure spot for local residents. People can enjoy good foods among small cafes among the old streets and alleys around the Confucius Temple and along with the famous Confucius Temple, tourists can also visit various monuments (see Fig. 10- Fig. 12).

\section{NEW APPROACH}

In response to problems in the frozen preservation of the old streets, the concept of the cultural district was developed in the 1990s and became a popular trend. Among important policies in the conservation of cultural district is basically the adaptive reuse. The idea is that a historic building undertakes adaptive reuse still retain its main characters as historical evidence. Such main characters are similar to what is called "integrity". William Murtagh argues that "integrity is at the heart of adaptive reuse"[6]. Brown Morton defines architectural integrity as "those qualities in a building and its site that give its meaning and value"[6]. Historicity in adaptive reuse is treated by sophisticated professionals as a catalyst to evoke new elements so that the new and the old as a whole can recapture the integrity of that particular historic building. Although adaptive reuse's results were so significant, it did not solve every problem within the conservation of a historic center. The new concept and approach of historic urban landscape offers a new solution.

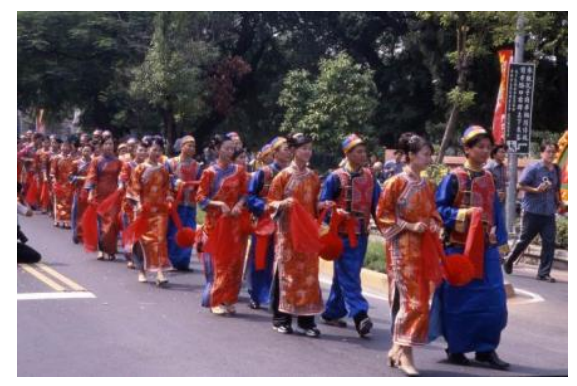

Fig. 12. Group wedding ceremony in the Tainan Confucius temple cultural district.
In other words, the Recommendation on the Historic Urban Landscape provides us with a new approach (the historic urban landscape approach) that is aimed at preserving the quality of the human environment, enhancing the productive and sustainable use of urban spaces, while recognizing their dynamic character, and promoting social and functional diversity. It integrates the goals of urban heritage conservation and those of social and economic development. It is rooted in a balanced and sustainable relationship between the urban and natural environment, between the needs of present and future generations and the legacy from the past (Article 11). The historic urban landscape approach considers cultural diversity and creativity as key assets for human, social and economic development, and provides tools to manage physical and social transformations and to ensure that contemporary interventions are harmoniously integrated with heritage in a historic setting and take into account regional contexts (Article 12) and the historic urban landscape approach learns from the traditions and perceptions of local communities, while respecting the values of the national and international communities(Article13). The trend to reuse and rejuvenate the urban heritage in the so-called cultural district, in some degree similar to ideas in the new historic urban landscape approach thought not completely the same. The conservation of the Tainan Confucius Temple Cultural District could be treated as an experiment.

Another example is the Annual Tainan Cisi Art Festival which is held in various temples in different cultural districts. On this festival, the adulthood-reaching rituals were performed which are closely related to the life of the people of the city (see Fig. 12). As a result, rituals performed and festivals held in monuments and historical buildings form a complete totality of tangible and intangible values in cultural heritages which will also become parts of the programs in cultural tourism.

\section{CONCLUSION}

Besides general conservation practices, the re-appreciation of intangible cultural heritage is also a trend in the cultural district conservation strategy. Around the last decade of the $20^{\text {th }}$ century, attitudes towards the cultural heritage among many countries started to change. UNESCO Recommendation on the Safeguarding of Traditional Culture and Folklore of 1989 marked a new epoch for the universal concern to protect the intangible cultural heritage. The recommendation is followed by the UNESCO Proclamation of Masterpieces of the Oral and Intangible Heritage of Humanity of 1997 and the UNESCO Universal Declaration on Cultural Diversity of 2001 and reached its climax in the UNESCO Convention for the Safeguarding of the Intangible Cultural Heritage and the Yamoto Declaration on Integrated Approach for the Safeguarding of Tangible and Intangible Cultural Heritage of 2004. The Article 10 of the Yamoto Declaration states that "taking into account the interdependence, as well as the differences between tangible and intangible cultural heritage, and between the approaches for their safeguarding, we deem it appropriate that, wherever possible, integrated approaches be elaborated to the effect 
that the safeguarding of the tangible and intangible heritage of communities and groups is consistent and mutually beneficial and reinforcing." The 2011 Recommendation on the Historic Urban Landscape placed urban heritage in a new context in which man-made objects, natural environment, tangible heritage, and intangible heritage are equally significance. The booklet New life for historic cities: The historic urban landscape approach explained published by UNESCO in 2013 clearly answered many questions on the issue [7] .

In Taiwan, although intangible cultural heritage has been discussed and included in the law, only a limited of people can properly tell the differences between tangible and intangible cultural heritages. The intangible cultural properties have been treated independently until the end of the $20^{\text {th }}$ century. Intangible values in the monuments and sites in Taiwan was rarely an issue in their conservation. From a certain points of view, intangible cultural heritage may be treated as an independent category of the cultural heritage. But strictly speaking, many of them are associated with the tangible cultural heritage. Cultural and religious activities in monuments and historical buildings started to be treated as the subjects for preservation in the Tainan Confucius Temple Cultural District. Festivals are encouraged to take place in various cultural heritages. For example, beginning from the 2000, annual Confucius Temple Cultural Festival is held in the Confucius Temple Cultural District to form a complete totality of tangible and intangible values in cultural heritages which will be reflected in the concept of historic urban landscape.

\section{REFERENCES}

[1] H. C. Lin, The Historic Outline of Cultural Heritage Conservation in Taiwan, Taipei: Yuanliu, 2011.

[2] C. C. Fu, A History of Modern Architecture in Taiwan, Taipei: The Architectural Institute of Taiwan, 2013.

[3] C. C. Fu, Architecture in Anping, Tainan: Scale, 1985

[4] C. C. Fu, "On the management of confucian temple cultural district in Tainan - from the observation of the international cultural tourism," in Proc. International Symposium on Cultural Property Conservation and Tourism, Tainan, Taiwan, 2005.

[5] H. C. Lin, Town and Street Structure of Lukang, Taichung, Chin Yu Hsiang Publisher, 1985.

[6] W. Murtagh, Keeping Time, Pittstown, New Jersey: The Main Street Press, p.118.

[7] New Life for Historic Cities: The Historic Urban Landscape Approach Explained, Paris: UNESCO.

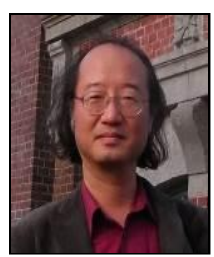

Chao-Ching Fu received his B.S. degree in architecture from the National Cheng Kung University in 1979, he received his M.Arch. degree from the University of Washington at Seattle, USA in 1983, and the Ph.D. degree from the University of Edinburgh, UK in 1990. Professor $\mathrm{Fu}$ is a leading architectural historian and an expert on heritage conservation. He has taught at the Department of Architecture, National Cheng Kung University since 1983 and lectured widely at many universities and institutes in Taiwan and other countries. Professor Fu has published hundreds of research papers and books since 1983 .

He received architectural award in Culture and Arts, Alberti Award for teaching and research on history of western architecture and NCKU distinguished professor award in 2009. In 2013, Professor Fu was awarded the fellowship of the architectural institute of Taiwan. 